\title{
Strategic Implications of Uncertainty over One's Own Private Value in Auctions
}

\author{
14 August 2006
}

Eric Bennett Rasmusen (2006) "Strategic Implications of Uncertainty over One's Own Private Value in Auctions," Advances in Theoretical Economics. Vol. 6: No. 1, Article 7. http://www.bepress.com/bejte/advances/vol6/iss1/art7

\section{Eric Rasmusen}

\begin{abstract}
A rational bidder in a private-value auction should be reluctant to incur the cost of perfectly estimating his value if it might not matter to the success of his bidding strategy. This can explain sniping - flurries of bids at the end of auctions - as the result of other bidders trying to avoid stimulating the victim into learning more about his value. The idea of value discovery also explains why a bidder might increase his bid ceiling in the course of an auction and why he would like to know the private values of other bidders.
\end{abstract}

Dan R. and Catherine M. Dalton Professor, Department of Business Economics and Public Policy, Kelley School of Business, Indiana University, BU 456, 1309 E. 10th Street, Bloomington, Indiana, 47405-1701. Office: (812) 855-9219. Fax: 812-855-3354. Erasmuse@indiana.edu. http:/ / www.rasmusen.org. Copies of this paper can be found at http:/ / www.rasmusen.org/papers/auction.pdf.JELCode:D44.

I thank Michael Fishman, David Hirshleifer, Michihiro Kandori, Roger Lagunoff, Dan Levin, James Peck, Michael Rothkopf, Jeffrey Stake, Lixin Ye, referees, and participants at seminars at Ohio State and Tokyo Universities for their comments (if not their agreement) and Lan Chang and Ariel Kemper for research assistance. I thank Harvard Law School's Olin Center and the University of Tokyo's Center for International Research on the Japanese Economy for their hospitality. 
Jeff happily awaited the end of the eBay auction. He had submitted a bid ceiling of $\$ 2,100$ for a custom-made analog stereo amplifier, and the highest anybody else had submitted was $\$ 1,400$, so he was sure to win. Since he'd followed the advice of eBay and academic auction theory, submitting his true maximum price, he looked forward to a cool $\$ 700$ in consumer surplus. It was five minutes before the auction deadline when disaster struck. The winning bid rose to $\$ 1,800$, and then $\$ 1,900$, and $\$ 2,000$. And then it rose to $\$ 2,150$, and Jeff was losing! Worse yet, as he feverishly thought hard about how much the amplifier was worth to him, he realized he actually would have been willing to pay $\$ 2,500$. But by then it was too late. The auction was over. ${ }^{1}$

\section{Introduction}

In an independent private-value auction, the value of the prize to each bidder is independent of the value to every other bidder. A bidder might like to learn other bidders' values if that affects how much they would bid, but that would not convey information about his own value. Under many auction rules, including the second-price sealed-bid auction, the open-exit auction, and common Internet auctions, knowledge of other bidders' values would be completely useless.

Here we will explore a simple change to the standard model that makes other bidders' values relevant: a bidder does not know his own value precisely but can learn it at a cost in time and money during the auction. Such a bidder would like to know other bidders' values before making his learning decision. Other players may or may not benefit from his learning, a new strategic consideration which helps explain the "sniping" to which Jeff fell prey.

"Value discovery" has a number of implications.

1. Bidders may increase their bid ceilings during the course of an open private-value auction such as the Internet auctions of eBay and Amazon.

2. Even in a second-price auction, a bidder might benefit from knowing how much other bidders are going to bid.

3. The discovery by a bidder of his private value might help a competing bidder and hurt the seller.

4. A bidder may purposely bid early and reveal his interest to provoke value discovery by another bidder.

5. A bidder may use "sniping" - submitting his bid at the last minute so as to deter another bidder's value discovery.

6. The seller can benefit from an "activity rule" requiring bidders to drop out permanently if they do not increase their bids steadily.

\footnotetext{
${ }^{1}$ From a story related to me by my law school colleague, Jeffrey Stake. I have used artistic license with details.
} 
Value discovery is an important part of practical auction strategy. In common-value auctions, a bidder makes complicated calculations using other bidders' bidding to learn about his own value. Private-value auctions seem easier, since the bidder does not have to make those calculations. This apparent simplicity overlooks how hard it is to estimate a private value. The bidder cannot look to other players' bids for help; he must figure out his own preferences. In a consumption auction such as an estate sale, he scratches his head and agonizes over whether the handsome old table will really match his other furnishings. In a business auction such as a corporate takeover, he hires consultants to estimate the synergies between his own company and the target.

Value discovery has been analyzed before, but for the most part only when it occurs before the auction starts, as in Dan Levin and James Smith (1994), in which bidders decide whether to pay a certain amount to learn their private values and enter an auction; Roland Guzman and Charles Kolstad (1999), a model of a sealed-bid private-value auction with possible information acquisition; and Jacques Cremer, Yossi Spiegel and Charles Zheng (2004), which looks at information acquisition in the intervals between a sequence of auctions. In a different style, Nicola Persico (2000) has studied the efficiency of incentives to acquire information, and shows that with independent private values the Vickrey mechanism is efficient. Donald Hausch and Lode $\mathrm{Li}$ (1993) also look at information acquisition, but in common-value auctions. In Olivier Compte and Philippe Jehiel (2004) and Tanjim Houssain (undated) a bidder does imprecisely estimate his private value, and his estimate can improve during the course of the auction. In that model, however, the improvement is exogenous - the bidder randomly and costlessly receives better information during the course of the auction. Houssain (undated) adds the wrinkle that the exogenous information depends on the current winning bid: it tells him whether his value is higher or lower than that bid.

As far back as 1988, Richard Engelbrecht-Wiggins noted that if information could be acquired over time in a multi-stage sealed-bid auction, efficiency would improve because bidders with a better chance of being the ultimate winner would be the ones willing to pay to acquire more information. Compte \& Jehiel (2005) compare $n$-bidder private-value ascending and second-price sealed-bid auctions when bidders can pay to learn about their private values during the course of the auction. They focus on the effect of the number of bidders and expected revenue, finding that the ascending auction (like other dynamic formats) leads to higher seller revenue. Leonardo Rezende (2005) constructs a similar model, finding that no player will acquire information before the bidding begins, that players' value discovery decisions are independent, and that ascending auctions typically yield more revenue than sealed-bid auctions.

\section{The Model}

The model will address a situation in which a bidder is uncertain about two things: his own value, and whether some other bidder has a higher value. The uncertain bidder's decision about whether to discover his value is the model's driving force. The other bidder's response 
supplies much of its interest.

Let there be two risk-neutral players, "the sniper" and "the victim", whose statistically independent private values $s$ and $v$ are distributed with strictly positive atomless and differentiable densities over the supports $[0, \bar{s}]$ and $[0, \bar{v}]$. The sniper's private value $s$ is distributed according to the density $g(s)$. He knows $s$, but not $v$. The victim's private value $v$ is distributed according to the density $f(v)$ with expected value $E(v)=\mu$. He knows neither $s$ nor $v$. At any time he may pay $c$ and learn $v$ after time $\delta$ has elapsed. For concreteness, assume that the sniper observes whether value discovery occurs (but this will not matter in equilibrium). The names "sniper" and "victim", taken from the context of Internet sniping, may be interpreted as "a bidder who knows his value" and "a bidder who must estimate his value".

Let the auction rule be the proxy bidding variety of the ascending auction. Each player submits a "bid ceiling". The "current winner" is the player with the highest bid ceiling, the "current winning bid" (which starts at zero) at a particular time. The auctioneer publicly posts the current winning bids, but not the bid ceilings. Denote the level of the current winning bid that induces the victim to discover his value as the "discovery threshold," $\bar{p}$. At any time, a player can increase his bid ceiling, but he cannot reduce it. At the end of the auction, the current winner wins the prize and pays the current winning bid. Proxy bidding differs from an open-exit auction because a bidder who has become inactive may re-enter later by submitting a new, higher, bid ceiling.

We will look at two ending rules. The "hard-ending" or "eBay" rule ends the auction at time $T$. The "soft-ending" or "Amazon" rule ends the auction either at time $T$, or $N>\delta$ minutes after the last bid ceiling is submitted, whichever is later.

We will consider three kinds of strategies. Using "estimation," the victim never pays to discover his value. Using "discovery" he pays to discover his value if the current winning bid rises to his discovery threshold. Using "prediscovery" he pays to discover his value before the auction begins.

\section{3a. The Soft-Ending Auction}

The soft-ending auction behaves much like a standard ascending auction.

Equilibrium: The sniper sets his bid ceiling equal to $s$. If $c>\bar{c}_{s o f t}$ the victim sets his bid ceiling equal to $\mu$ and never discovers $v$. If $c \leq \bar{c}_{s o f t}$, he sets his discovery threshold and initial bid ceiling equal to $\bar{p}_{\text {soft }} \in(0, \mu)$ and he raises his bid ceiling to $v$ if he discovers that $v>\bar{p}_{\text {soft }}$. Equations (5) and (6) below characterize $\bar{c}_{\text {soft }}$ and $\bar{p}_{\text {soft }}$.

\section{Explanation}


(a) The sniper sets his bid ceiling equal to $s$ for the usual reason that this bid ceiling weakly dominates any other in ascending auctions; he does not risk losing the auction when he is willing to pay more than the winning bid, or risk winning at a price greater than his value. If the sniper were to submit his bid ceiling just before $T$ to try to prevent value discovery he would fail. The auction would be extended $N$ minutes and the victim would have available the $\delta$ minutes needed to discover $v$ and possibly increase his bid ceiling.

(b) The victim, having observed that the current winning bid has risen to level $p$, must decide whether he would prefer to continue raising his bid, to pause and discover his value $v$, or to drop out. The decision at $p$ matters only if $s=p$ (so the sniper is going to drop out at $p$ )otherwise, the crucial decision is at some higher level of current winning bid- so let's condition on $s=p .^{2}$ Dropping out has payoff zero. Continuing without value discovery results in winning at price $p$, which has a positive payoff if $p<\mu$. This payoff averages the loss when $v<p$ and the gain when $v>p$, equalling (where $F(p)$ of probability is already "used up" before reaching $p$ ),

$$
\pi(\text { estimation } \mid s=p)=\int_{0}^{p}(v-p)\left(\frac{f(v)}{1-F(p)}\right) d v+\int_{p}^{\bar{v}}(v-p)\left(\frac{f(v)}{1-F(p)}\right) d v
$$

Value discovery results in either discovering that $v<p$ and dropping out, or discovering that $v>p$ and staying in to win at price $p$. The expected payoff is

$$
\pi(\text { discovery } \mid s=p)=-c+\int_{0}^{p}(0)\left(\frac{f(v)}{1-F(p)}\right) d v+\int_{p}^{\bar{v}}(v-p)\left(\frac{f(v)}{1-F(p)}\right) d v
$$

Since $c>0$, and $f(v)$ has no atom at $v=0$, for small enough $p$, payoff (1) is close to $\int_{0}^{\bar{v}}(v-0) f(v) d v /(1-F(p))$ and payoff $(2)$ is close to $-c+\int_{0}^{\bar{v}}(v-0) f(v) d v /(1-F(p))$. For small enough $p$, estimation is thus better than discovery, and the optimal discovery threshold is positive: $\bar{p}_{\text {soft }}>0$.

(c) The advantage of discovery over estimation is

$$
\pi(\text { discovery } \mid s=p)-\pi(\text { estimation } \mid s=p)=-c+\int_{0}^{p}(p-v)\left(\frac{f(v)}{1-F(p)}\right) d v
$$

This advantage rises monotonically in $p$, because its derivative with respect to $p$ is

$$
\int_{0}^{p}\left(\frac{f(v)}{1-F(p)}+(p-v) \frac{f(v) f(p)}{[1-F(p)]^{2}}\right) d v>0
$$

${ }^{2}$ This payoff would be the same if the victim instead followed the strategy of raising his bid ceiling to some value such as $\mu$ if the current winning bid never reached the bid ceiling-a higher bid ceiling would then make no difference. 
If $p$ rises as high as $\mu$, the the estimation payoff, expression (1), is zero. The discovery payoff, expression (2), is positive at $p=\mu$ if (and only if) $c<\bar{c}_{s o f t}$, where

$$
\bar{c}_{s o f t}=\int_{\mu}^{\bar{v}}(v-\mu)\left(\frac{f(v)}{1-F(p)}\right) d v
$$

Thus, if $c>\bar{c}_{s o f t}$, the victim follows the estimation strategy of never discovering his value, but otherwise he chooses to discover his value at some $\bar{p}_{\text {soft }}<\mu$.

(d) If $c<\bar{c}_{s o f t}$, then since the advantage of estimation over discovery is monotonic, positive at $p=0$, and negative at $p=\mu$, there exists an optimal discovery threshold $\bar{p}_{\text {soft }}$ defined implicitly using expression (3) by

$$
\int_{0}^{\bar{p}_{s o f t}}\left(\bar{p}_{s o f t}-v\right)\left(\frac{f(v)}{1-F\left(p_{s o f t}\right)}\right) d v=c
$$

As $c$ increases, so does $\bar{p}_{\text {soft }}$.

The victim's benefit from increasing $\bar{p}_{\text {soft }}$ is that his probability of paying the discovery cost falls. The disadvantage is that a winning price below $\bar{p}_{\text {soft }}$ might exceed his value: $p>v$, which value discovery would have prevented. The size of the disadvantage depends on the likelihood that $v$ is below $\bar{p}_{\text {soft }}$. If $\bar{p}_{\text {soft }}=0$, the disadvantage vanishes. The victim should increase his initial bid ceiling until the marginal gain from avoiding the discovery cost equals the marginal loss from winning when his value is below the price.

The discovery threshold does not depend on the number or the value densities of other bidders, something Rezende (2005) has also found. What the victim cares about is how his expected loss from paying more than $v$ rises as $\bar{p}_{\text {soft }}$ increases, not how likely it is that the current winning bid reaches $\bar{p}_{\text {soft }}$. His marginal decision only matters if the current winning bid actually reaches $\bar{p}_{\text {soft }}$, and once that happens its ex ante probability is irrelevant.

Thus, the victim increases his bid ceiling if the current winning bid rises to $\bar{p}_{\text {soft }}$ and his value discovery reveals that $v>\bar{p}_{s o f t}$. This yields the first of the phenomena listed in the Introduction:

\section{Bidders may increase their bid ceilings during the course of an ascending private value auction.}

If all bidders knew their values in advance, they would submit their values as bid ceilings, and the timing of when they submitted bid ceilings would not matter. Here, a better strategy is to start with a low bid ceiling and revise it upward later. This helps in two ways. First, the victim purposely starts with a bid ceiling lower than his expected value so he can drop out if he 
discovers his value is low. Second, he might discover that his value actually exceeds its expected value.

In Rasmusen (2005) I use this idea to explain the phenomenon of bidders apparently "getting carried away". Phenomenon (1) will arise in any model of value discovery, and so also can be found in Compte \& Jehiel (2005) and Rezende (2005), which note that the revenue equivalence theorem fails because bidders cannot increase their bid ceilings in the course of a sealed-bid auction. Kent Daniel and David Hirshleifer (1998) tell a story in which each bid is costly, and this leads to a series of jump bids, rather than just a pre-emptive bid at the start. One bidder's jump bid to signal his high valuation may lead to another bidder doing the same. Bids stimulate discontinuous behavior, but each player knows his own valuation, so what the pre-empting player is trying to do is to show the other player that further bidding is useless.

\section{The Hard-Ending Rule}

Under the hard-ending rule, bid ceilings cannot be updated after time $T$, regardless of when the current winning bid last increased. The victim thus cannot usefully discover his value in response to bids observed after time $(T-\delta)$.

Equilibrium: For the values of $s^{*}, \bar{p}_{h}, \bar{c}_{h}$, and $\underline{c}_{h}$ specified in equations (9), (13), (17), and (19), bidders follow the strategies below.

\section{Case i: $c<\underline{c}_{h} \quad$ (Prediscovery is best)}

Victim: Discover $v$ no later than $(T-\delta)$ and submit a bid ceiling of $v$ no later than $T$.

Sniper: Submit a bid ceiling of $s$ no later than $T$.

Case ii: $c \in\left[\underline{c}_{h}, \bar{c}_{h}\right]$ (Discovery is best)

Victim: Submit a bid ceiling of $\bar{p}_{h}$ before $(T-\delta)$. If the current winning bid rises to $\bar{p}_{h}$ before or at $(T-\delta)$, pay $c$ and discover $v$. Then, if $v>\bar{p}_{h}$, increase the bid ceiling to $v$ no later than $T$ and otherwise increase it to $\mu$.

Sniper: (1) If $s<s^{*}$, submit a bid ceiling of $s$ at time $t^{\prime}<T$.

(2) If $s \geq s^{*}$, snipe. At time $t^{\prime}$ (the same $t^{\prime}$ as in (1)) submit a bid ceiling of $p$ obtained by mixing with density $m(p)=\frac{g(p)}{G\left(\bar{p}_{h}\right)}$ over $\left[0, \bar{p}_{h}\right]$. At time $t^{\prime \prime} \in(T-\delta, T]$, with $t^{\prime \prime}>t^{\prime}$, submit a bid ceiling of s.

Case iii: $c>\bar{c}_{h} \quad$ (Estimation is best)

Victim: Submit a bid ceiling of $\mu$ no later than $T$. Never discover $v$.

Sniper: Submit a bid ceiling of $s$ no later than $T$. 
The rest of Section 4 will explain this equilibrium.

\section{(a) Bidding strategies in cases (i) and (iii)}

For the same reasons as in the soft-ending auction, the victim's bid ceiling at the end of the auction should be his value $v$ if he knows it and his expected value $\mu$ otherwise, and the sniper's should be his value $s$. This justifies the equilibrium bidding strategies in cases (i) and (iii). The bidding strategies in case (ii) and the discovery thresholds in all three cases need more extended explanation.

\section{(b) The sniper's bidding strategy in case (ii)}

The sniper would clearly like the victim to discover $v$ if $s<\mu$, because otherwise the victim will eventually raise his bid ceiling to $\mu$ and win, whereas if the victim discovers $v$ it might happen that $v<s$ and the sniper wins. Thus, a sniper with a value below $\mu$ should bid early to stimulate the victim to discover $v$.

When $s>\mu$, value discovery's benefit to the sniper is less clear. His expected payoff has three parts, depending on whether he wins at a price of $\bar{p}_{h^{\prime}}$ wins at a price of $v>\bar{p}_{h^{\prime}}$ or loses.

$$
E\left(\pi_{s}^{\text {discover }}(s \mid s \geq \mu)\right)=\int_{0}^{\bar{p}_{h}}\left(s-\bar{p}_{h}\right) f(v) d v+\int_{\bar{p}_{h}}^{s}(s-v) f(v) d v+\int_{s}^{\bar{v}}(0) f(v) d v
$$

If, instead, he prevents value discovery by sniping, his expected payoff is

$$
E\left(\pi_{s}^{\text {not discover }}(s \mid s \geq \mu)\right)=s-\mu
$$

The advantage $Z(s)$ of provoking discovery is (7) minus (8), which equals zero at the optimal switch value $s^{*}$. Thus, $s^{*}$ solves

$$
Z\left(s^{*}\right)=\mu-\int_{0}^{\bar{p}_{h}} \bar{p}_{h} f(v) d v-\int_{\bar{p}_{h}}^{s^{*}} v f(v) d v-\int_{s^{*}}^{\bar{v}} s^{*} f(v) d v=0
$$

When $s<s^{*}$, the sniper wants the victim to discover $v$. Above $s^{*}$, he does not.

The value of $s^{*}$ in equation (9) cannot exceed $\bar{s}$, the maximum possible value of $s$. The sniper benefits from value discovery if $s$ is less than $\mu$, so $s^{*} \geq \mu$. Finally, the biggest possible value of $v, \bar{v}$, is above $s^{*}$, since

$$
Z(\bar{v})=\mu-\int_{0}^{\bar{p}_{h}} \bar{p}_{h} f(v) d v-\int_{\bar{p}_{h}}^{\bar{v}} v f(v) d v-\int_{\bar{v}}^{\bar{v}} \bar{v} f(v) d v=\int_{0}^{\bar{p}_{h}}\left(v-\bar{p}_{h}\right) f(v) d v<0
$$

The threshold $s^{*}$ therefore lies somewhere in the interval $(\mu, \bar{v})$. 
The purpose of the sniper's mixing is not to prevent the victim from being able to predict the action mixed over, but to prevent him from using the observed action to deduce the sniper's type. It is signal jamming, not evasion. The sniper's early bid never affects whether he wins or how much he pays, and helps only because if there were no early bid the victim could deduce that $s>s^{*}$. The mixing density $m(p)=\frac{g(p)}{G\left(\bar{p}_{h}\right)}$ provides minimal information to the victim, since it spreads the probability of sniper being present proportionately across the values of $p$ for which the victim has not discovered $v$. While it remains true that the mixing player is indifferent among the actions between which he mixes, the indifference is not knife-edge and the action has no direct effect on the payoff. There is room for other equilibria, with slightly different mixing densities that would also prevent the victim from interpreting any particular current winning bid as sure evidence of a lurking sniper.

\section{(c) The victim's bidding strategy in case (ii)}

The victim's strategy requires him to raise his bid ceiling from $\bar{p}_{h}$ to $\mu$ if the current winning bid never reaches $\bar{p}_{h}$. This doesn't matter on the equilibrium path, because the bid ceiling would only remain at $\bar{p}_{h}$ if the sniper's value were below $\bar{p}_{h}$ or above $s^{*}$. If the victim followed a strategy in which he did not thus raise his bid ceiling, however, the sniper would deviate from his own equilibrium strategy. If, for example, $s$ were slightly below $s^{*}$, he could profit by initially bidding less than $\bar{p}_{h}$ and then raising his bid ceiling to $s$ after time $(T-\delta)$. That deviation would allow him to win at the price $\bar{p}_{h}$, which would be more profitable than stimulating value discovery.

\section{(d) The precise value of the discovery threshold, $\bar{p}$}

Suppose the current winning bid in case (ii) rises from zero to some value $p$ less than $\bar{p}_{h}$ and halts. In equilibrium, this happens for one of two reasons: (1) With density $g(p)$, it happens that $s=p$ and the sniper has bid his value; (2) With probability $\left[1-G\left(s^{*}\right], s \in\left[s^{*}, \bar{s}\right]\right.$, the sniper has submitted a low bid using the mixing density $m(p)$ to mask his true value. The victim should therefore update his beliefs about $s$ from his prior, density $g(s)$, to put a mass of probability on $s=p$ and a density on values of $s$ in $\left[s^{*}, \bar{s}\right]$ based on the mixing probability. 
Using Bayes' Rule, his posterior is therefore

$$
\begin{array}{lll}
\operatorname{Density}(s) & =0 & \text { if } s<p \\
\operatorname{Probability}(s)=\frac{(1) g(p)}{g(p)+m(p)\left[1-G\left(s^{*}\right)\right]}=\frac{g(p)}{g(p)+\frac{g(p)}{G\left(\bar{p}_{h}\right)}\left[1-G\left(s^{*}\right)\right]}=\frac{G\left(\bar{p}_{h}\right)}{1-\left[G\left(s^{*}\right)-G\left(\bar{p}_{h}\right)\right]} & \text { if } s=p \\
\text { Density }(s) & =0 & \text { if } s \in\left(p, s^{*}\right) \\
\operatorname{Density}(s)=\frac{m(p) g(s)}{g(p)+m(p)\left[1-G\left(s^{*}\right)\right]}=\frac{\frac{g(p)}{G\left(\bar{p}_{h}\right)} g(s)}{g(p)+\frac{g(p)}{G\left(\bar{p}_{h}\right)}\left[1-G\left(s^{*}\right)\right]} & =\frac{g(s)}{1-\left[G\left(s^{*}\right)-G\left(\bar{p}_{h}\right)\right]} & \text { if } \quad s \geq s^{*}
\end{array}
$$

The bidding having reached $p$, the victim has a choice between paying to discover his value and not paying. If he pays and discovers, he wins the prize at a price of $p$ if $s=p$ or a price of $s$ if $s \in\left[s^{*}, \bar{v}\right]$ and $v>s$. If he does not discover, he wins only if $s=p$. His expected payoffs are therefore, using the probabilities from equation (11) and conditioning on $s$ either equalling $p$ or exceeding $s^{*}$,

$$
\begin{aligned}
\pi(\text { discovery } \mid p)= & -c+\left(\frac{G\left(\bar{p}_{h}\right)}{1-\left[G\left(s^{*}\right)-G\left(\bar{p}_{h}\right)\right]}\right) \int_{p}^{\bar{v}}(v-p)\left(\frac{f(v)}{1-F(p)}\right) d v \\
& +\int_{s^{*}}^{\bar{s}}\left[\int_{s}^{\bar{v}}(v-s)\left(\frac{f(v)}{1-F(p)}\right) d v\right]\left(\frac{g(s)}{1-\left[G\left(s^{*}\right)-G\left(\bar{p}_{h}\right)\right]}\right) d s \\
\pi(\text { estimation } \mid p)= & \left(\frac{G\left(\bar{p}_{h}\right)}{1-\left[G\left(s^{*}\right)-G\left(\bar{p}_{h}\right)\right]}\right) \int_{0}^{\bar{v}}(v-p)\left(\frac{f(v)}{1-F(p)}\right) d v
\end{aligned}
$$

The advantage of estimation over discovery, $[\pi($ estimation $\mid p)-\pi($ discovery $\mid p)]$, is zero if

$$
\begin{aligned}
& \left(\frac{G\left(\bar{p}_{h}\right)}{1-\left[G\left(s^{*}\right)-G\left(\bar{p}_{h}\right)\right]}\right) \int_{0}^{p}(v-p)\left(\frac{f(v)}{1-F(p)}\right) d v+c \\
& -\int_{s^{*}}^{\bar{s}}\left[\int_{s}^{\bar{v}}(v-s)\left(\frac{f(v)}{1-F(p)}\right) d v\right]\left(\frac{g(s)}{1-\left[G\left(s^{*}\right)-G\left(\bar{p}_{h}\right)\right]}\right) d s=0
\end{aligned}
$$

Equation (13) characterizes $p=\bar{p}_{h}$.

\section{(e) Prediscovery and the precise values of the parameter boundaries $\underline{c}_{h}$ and $\bar{c}_{h}$}

Unlike under the soft-ending rule, we now need to consider separately the victim strategy of prediscovering $v$ before the auction begins. If $\bar{p}_{h}>0$, then the sniper can "hide" by initially 
bidding in the interval $\left[0, \bar{p}_{h}\right]$, but if $\bar{p}_{h}=0$ he cannot. This creates a discontinuity, so the payoff from prediscovery is not the same as the payoff from discovery evaluated at $\bar{p}_{h}=0$. The payoffs from the three possible strategies at the start of the auction are as follows.

The victim's payoff from the estimation strategy, $\pi($ estimation $\mid p=0)$ is the value of winning when $s<\mu$, which equals

$$
=\int_{0}^{\mu}\left(\int_{0}^{\bar{v}}(v-s) f(v) d v\right) g(s) d s
$$

The payoff from the discovery policy of waiting to discover at $p=\bar{p}_{h}$ is $\pi($ discovery $\mid p=0)$, which equals

$$
\begin{aligned}
& \int_{0}^{\bar{p}_{h}}\left(\int_{0}^{\bar{v}}(v-s) f(v) d v\right) g(s) d s+\int_{\bar{p}_{h}}^{s^{*}}\left(\int_{s}^{\bar{v}}(v-s) f(v) d v\right) g(s) d s-\int_{\bar{p}_{h}}^{s^{*}} c g(s) d s \\
= & \int_{0}^{\mu}\left(\int_{0}^{\bar{v}}(v-s) f(v) d v\right) g(s) d s-\int_{\bar{p}_{h}}^{\mu}\left(\int_{0}^{\bar{v}}(v-s) f(v) d v\right) g(s) d s \\
& +\int_{\bar{p}_{h}}^{s^{*}}\left(\int_{s}^{\bar{v}}(v-s) f(v) d v\right) g(s) d s-\int_{\bar{p}_{h}}^{s^{*}} c g(s) d s
\end{aligned}
$$

The value of $\pi$ (prediscovery $\mid p=0)$ is:

$$
\begin{aligned}
& \int_{0}^{\bar{v}}\left(\int_{s}^{\bar{v}}(v-s) f(v) d v\right) g(s) d s-c \\
= & \int_{\bar{p}_{h}}^{s^{*}}\left(\int_{s}^{\bar{v}}(v-s) f(v) d v\right) g(s) d s+\int_{0}^{\bar{p}_{h}}\left(\int_{s}^{\bar{v}}(v-s) f(v) d v\right) g(s) d s \\
& +\int_{s^{*}}^{\bar{v}}\left(\int_{s}^{\bar{v}}(v-s) f(v) d v\right) g(s) d s-c+\int_{0}^{\mu}\left(\int_{0}^{\bar{v}}(v-s) f(v) d v\right) g(s) d s \\
& -\int_{\bar{p}_{h}}^{\mu}\left(\int_{0}^{\bar{v}}(v-s) f(v) d v\right) g(s) d s-\int_{0}^{\bar{p}_{h}}\left(\int_{0}^{\bar{v}}(v-s) f(v) d v\right) g(s) d s
\end{aligned}
$$

Setting the advantage of discovery over estimation from (14) and (15) equal to zero and solving for $c$ yields

$$
\bar{c}_{h}=\left(\frac{1}{G\left(s^{*}\right)-G\left(\bar{p}_{h}\right)}\right)\left[\int_{\bar{p}_{h}}^{s^{*}}\left(\int_{s}^{\bar{v}}(v-s) f(v) d v\right) g(s) d s-\int_{\bar{p}_{h}}^{\mu}\left(\int_{0}^{\bar{v}}(v-s) f(v) d v\right) g(s) d s\right]
$$


From expressions (15) and (16). the advantage of prediscovery over discovery is

$$
\begin{aligned}
& \int_{s^{*}}^{\bar{s}}\left(\int_{s}^{\bar{v}}(v-s) f(v) d v\right) g(s) d s+\int_{0}^{\bar{p}_{h}}\left(\int_{s}^{\bar{v}}(v-s) f(v) d v\right) g(s) d s \\
& -\int_{0}^{\bar{p}_{h}}\left(\int_{0}^{\bar{v}}(v-s) f(v) d v\right) g(s) d s-c+\left[G\left(s^{*}\right)-G\left(\bar{p}_{h}\right)\right] c \\
& =\int_{s^{*}}^{\bar{s}}\left(\int_{s}^{\bar{v}}(v-s) f(v) d v\right) g(s) d s-\int_{0}^{\bar{p}_{h}}\left(\int_{0}^{s}(v-s) f(v) d v\right) g(s) d s-c+\left[G\left(s^{*}\right)-G\left(\bar{p}_{h}\right)\right] c
\end{aligned}
$$

If $c$ is small enough, prediscovery is better than discovery. The critical value is

$$
\underline{c}_{h}=\left(\frac{1}{1-\left[G\left(s^{*}\right)-G\left(\bar{p}_{h}\right)\right]}\right)\left[\int_{s^{*}}^{\bar{s}} \int_{s}^{\bar{v}}(v-s) f(v) d v g(s) d s-\int_{0}^{\bar{p}_{h}} \int_{0}^{s}(v-s) f(v) d v g(s) d s\right]
$$

\section{Example}

Suppose the probability $G$ that $s$ lies in the interval $(\mu, \bar{s}]$ is small enough and the probability that $s$ lies in the interval $(0, c]$ is large enough. Then, since $s^{*}>\mu$, it follows that $G\left(s^{*}\right) \approx 1$ and equation (13), which defined $\bar{p}_{h}$, is arbitrarily close to

$$
-c-\int_{0}^{\bar{p}_{h}}\left(v-\bar{p}_{h}\right) f(v) d v+0=0 .
$$

Equation (20) can only be true if $\bar{p}_{h}>c$ (intuitively: it is not worth paying $c$ for value discovery to avoid overpaying for the prize by some amount less than $c$ ).

If the probability that $s$ lies in the interval $(\mu, \bar{s}]$ is small enough, expression (??) becomes close to

$$
\begin{aligned}
& \int_{\bar{p}_{h}}^{\mu}\left(\int_{s}^{\bar{v}}(v-s) f(v) d v\right) g(s) d s-\int_{\bar{p}_{h}}^{\mu}\left(\int_{0}^{\bar{v}}(v-s) f(v) d v\right) g(s) d s-\left[G(\mu)-G\left(\bar{p}_{h}\right)\right] c \\
& =-\int_{\bar{p}_{h}}^{\mu}\left(\int_{0}^{s}(v-s) f(v) d v\right) g(s) d s-\left[G(\mu)-G\left(\bar{p}_{h}\right)\right] c,
\end{aligned}
$$

which is positive for small enough $c$. Thus, discovery is better than estimation.

Also, since $G\left(\bar{p}_{h}\right)$ is close to 1 , expression (18) becomes close to

$$
\begin{aligned}
& 0+\int_{0}^{\bar{p}_{h}}\left(\int_{0}^{s}(v-s) f(v) d v\right) g(s) d s-c+[1-1] c \\
& =-\int_{0}^{\bar{p}_{h}}\left(\int_{0}^{s}(v-s) f(v) d v\right) g(s) d s-\left(-\int_{0}^{\bar{p}_{h}}(v-p) f(v) d v\right)<0
\end{aligned}
$$


where this last step substitutes for $c$ using equation (20). Thus, discovery is also better than prediscovery.

3

If $c$ is low enough, on the other hand, prediscovery has the highest payoff, adding benefit that must be balanced against a low cost of $\left[1-G\left(s^{*}\right)+G\left(\bar{p}_{h}\right)\right] c$. And if $c$ is high enough, estimation has the highest payoff.

\section{Phenomena Explained by the Hard-Ending Auction Model}

We can now return to the remaining phenomena listed in the Introduction.

2. Even in a second-price auction, a bidder might benefit from knowing how much other bidders are going to bid.

The victim would not have to spend $c$ if he knew that the sniper's value was low. In a standard second-price private value auction, knowing other players' values or even their bids is unhelpful because the knowledge would not affect a bidder's strategy (unlike in a first-price auction, where it would help him to win with a lower bid). Here, that knowledge is useful because it helps the victim avoid sniping, by deciding to pay to discover his value.

This is essentially the same point as Proposition 4.1 of Sandholm (2000), an article pointing out the practical limitations of Vickrey auctions. It is also a natural result of any model of value discovery and so is implicit in the models of Compte \& Jehiel (2005) and Rezende (2005). Larson \& Sandholm (2001) emphasize a similar conclusion, that the possibility of learning about one's own value can make learning a competing bidder's value worthwhile, though in a different style of model, in which bidders are boundedly rational and must decide whether to incur costs to learn about their own and other bidders' values. Larson and Sandholm show that these decisions are connected, and that a bidder might use some of his "limited deliberation resources" on another player's valuation problem as well as his own.

3. The discovery by a bidder of his private value might help a competing bidder and hurt the seller.

If $s \in\left[\bar{p}_{h}, \mu\right]$, the sniper would like to stimulate value discovery if he could. The victim would like it too, to know how high to bid. But the effect of these two things is to reduce the expected price, so the seller loses. That the seller can lose when the victim learns $v$ can also be found in footnote 15 of Rezende (2005), which attributes the idea to Paul Milgrom. The result must be treated with care. It contrasts sharply with the findings in Compte \& Jehiel (2005) and Rezende (2005) that if the number of bidders is high enough the seller's revenue is higher in an ascending auction, in which there can be value discovery, than in a second-price sealed-bid auction. The key difference is that with only two bidders the victim is sure to be either the

\footnotetext{
${ }^{3} x x x$ Add INTUITION HERE, AND CONNECTION.
} 
highest bidder (whose value does not directly affect the winning price) or the second-highest (whose value is the winning price). If there were more bidders, the victim would not always be the second-highest bidder before he knew his value, so discovering that his value was low would not always reduce the winning price.

In the standard private-value auction model, the timing of bids is unimportant. If there were no value discovery in the model- or if value discovery could occur at any time, as in the soft-ending auction- then it would make no difference whether the sniper bid early or late. In the hard-ending auction, it does matter, yielding the last three phenomena.

4. A bidder may purposely bid early and reveal his interest to provoke value discovery by another bidder.

5. A bidder may use "sniping" - submitting his bid at the last minute so as to deter another bidder's value discovery.

6. The seller can benefit from an "activity rule" requiring bidders to drop out permanently if they do not increase their bids steadily.

If $s \in\left[\bar{p}_{h}, s^{*}\right]$ the sniper wants to stimulate value discovery, so he should submit a bid ceiling of $\bar{p}_{h}$ before time $(T-\delta)$. The advantage of stimulating value discovery is that the victim might discover that $v<\mu$ and bid less than the $\mu$ he would bid if he stayed uninformed. The disadvantage is that the victim might discover that $v>\mu$ and bid higher, which either makes the sniper pay more to win or actually exceeds the sniper's value and makes him lose. For low enough values of $s$, the sniper's tradeoff is in favor of value discovery.

Thus, if the sniper's value is not too high, he makes what looks like a pre-emptive bid, not for the usual reason of deterring entry, but to prompt another player to buy costly information and perhaps exit the auction. He wants to show that because of tight competition the victim should think carefully before he stays in. If $s>s^{*}$, however, the tradeoff goes the other way. If value discovery results in the sniper losing because $v>s$, the lost surplus is greater than when $s$ takes lower values. A victory yielding a surplus of $(s-\mu)$ is replaced by a surplus of zero, a more painful replacement if $s$ is high.

Because of sniping, activity rules can help raise the seller's revenue. This is related to the finding of Compte and Jehiel (2005) and Rezende (2005) that ascending or multi-stage auctions are better than sealed-bid ones. In an ascending auction without a requirement that a bidder stay active, sniping can occur. If the bidder must continue to show his willingness to match the current winning bid, sniping is not possible.

Other reasons for sniping exist, and should be mentioned here. The simplest alternative reason is that the prize actually has a common value (see Patrick Bajari \& Ali Hortacsu [2003]). If time is required for updating valuations, then since there is a value component common to all bidders, whenever someone raises his bid the other bidders will revise their value estimates upwards and bid more, to his detriment. Hence, he should delay bidding until it is too late for 
them to revise their estimates. This explanation, phrased less technically, can be found with others at the website, "Advanced Auction Management," which lists a number of practical reasons for bidding late. ${ }^{4}$

A second reason is that a late bidder does not have to commit to buy an item only to find something later that he would rather buy - as in Compte \& Jehiel (2004), in which a bidder randomly acquires exogenous information about his value. This kind of late bidding is "defensive" rather than "offensive"; it would apply even if there were only one bidder and a seller with a reserve price. Closely related is that late bidding lets the bidder know quickly whether he has successfully bought the item, so he can move on to another source if he loses.

Another reason for sniping is to avoid "shilling" by sellers. Sellers in Internet auctions are strictly forbidden to bid on their own items, although they may establish a reserve price before the auction begins, since otherwise a seller could see how much the highest-valuing bidder was willing to pay and charge him that price. Shilling is hard to catch because sellers can use anonymous email addresses to bid. If such strategizing by the seller takes time, however, it can be evaded by bidding close to the deadline. Irrationality can also explain players increasing their reservation bids over the course of an auction (see Gillian Ku, Deepak Malhotra \& Keith Murnighan [2005]), and this, too would make sniping a rational response. The cost of returning to a multi-day auction to re-bid has been shown by Octavian Carare and Michael Rothkopf (2005) to make open-cry Dutch auctions different from sealed-bid auctions. That would combine with several of these reasons to make it attractive to bid late, after the early bidders are no longer watching. Finally, Alvin Roth \& Axel Ockenfels (2002) have a different explanation. Players making bids in the last minute may find the computer has not been able to get their bids in time. In that case, players will submit low bids early in the auction and higher bids in the last minute. There is some chance that none of the high bids will be accepted, and so some bidder wins with his low initial bid. If, on the other hand, someone tries bidding higher before the last minute, so his bid definitely reaches eBay, he finds that other bidders will outbid him and the resulting bidding war will leave even the winner with a low payoff. ${ }^{5}$

\section{Robustness of the Model: What if the Victim Makes Mistakes?}

Contrary to the conclusions of the present model, auction theory's usual advice is to choose the strategy of submitting one's private value. The eBay website instructions say:

\footnotetext{
4"Advanced Auction Management," http://www.tblightning.com/ebay/auction_management.htm (Jan 27, 2002).

${ }^{5}$ This has some similarity to Bertrand models of price competition, where marginal-cost pricing is Nash, but weakly dominated, and so disappears when noise is added. See, for example, Maarten Janssen \& Eric Rasmusen (2001), in which $N$ identical firms each may be active or inactive, and post prices for a consumer. Each firm knows that it might be the only active firm, so it charges a price higher than marginal cost, using a mixed strategy. As in Roth \& Ockenfels, a little bit of noise in a Bertrand model (in their case, the possibility last-minute bids might not get through) results in the competing price-setters ending up with positive expected profits.
} 
"For example, if the current bid on an item is $\$ 5$ and you are willing to pay up to $\$ 10$, you would enter $\$ 10$ as your maximum bid. Your bid would be shown on the item page as $\$ 5$, but if another bidder places a bid for $\$ 6$, then eBay will place a higher bid on your behalf. The bid would be just above the other member's bid. This would continue until either you win the auction at or below $\$ 10$ or the bidding exceeds the $\$ 10$ you were willing to pay. eBay will notify you via email if you are outbid and you can return to place another bid if you like. Your maximum bid is never disclosed to other bidders or to the seller." 6

Ronald Wilcox (2000) investigates the pattern of bidding in eBay auctions for consumer items and finds that less experienced bidders submit their bids earlier than more experienced bidders. 1.2 percent of the least experienced bidders bid during the last minute, compared to 8.2 percent of the most experienced bidders. The effect is present with both private values and common values, though most pronounced for common values. ${ }^{7}$

Alvin Roth and Axel Ockenfels (2002) have also investigated Internet auctions. They find that eBay auctions have more sniping than Amazon auctions. In the last hour of the auction, 20 percent of all final eBay bids are submitted, but only 7 percent of final Amazon bids, and in the last five minutes 9 and 16 percent (for computers vs. antiques) of eBay bidders submit their bids but only 1 percent of Amazon bidders. The difference is even clearer with experienced bidders, who in eBay auctions submit bids later than the inexperienced bidders but in Amazon auctions submit earlier. Roth and Ockenfels also surveyed bidders who bid in the last minute. Most of the some 70 bidders who replied said they bid late consciously to keep prices down. Some said they were influenced in their values by the bids of other people, but 88 percent of late bidders said that they had a clear idea of their value at the start of the auction. A few (less than 10 percent) seem to have been confused about the auction rule and thought they had to bid late to win.

Jeff Ely and Tanjim Houssain (2006) look at internet auctions of newly released DVD's. They themselves bid, to test the difference between the payoffs from early bidding and from sniping. Sniping has the higher payoff, which they conclude is because many auctions are run concurrently for the same prize and because some bidders are naive, and behave as if it were a standard English auction.

In the context of the value discovery model, let us think about the effects of two kinds of mistakes the victim might make: not understanding the value of early discovery, and not understanding the possibility of sniping. Does the value discovery model require too high a level of bidder sophistication?

\footnotetext{
${ }^{6}$ eBay Tutorials, "Place Your Bid" http:/ / pages.eBay.com/education/tutorial/course1/bidding.html (May 25, 2002)

${ }^{7}$ Wilcox also tries to approach the question of whether less experienced bidders increase their bids during the course of the auction. This is difficult because the public data does not say whether a bidder has increased his bid. It does, however, have the total number of bids and bidders. Wilcox finds no significant difference in number of bids per bidder in auctions for private-value goods where average experience is higher, but he finds that the number of bids per bidder is higher for common-value goods.
} 
The first mistake is to ignore the value of early discovery and simply follow the eBay instructions to bid one's value, as opposed to first submitting a bid ceiling of $\bar{p}_{h}<\mu$ and later raising the bid ceiling if value discovery reveals that $v>\bar{p}_{h}$. Such a bidder would not understand that waiting to submit a high bid ceiling has option value- that by submitting a low initial bid ceiling he could preserve the option not to bid higher if he finds his value is lower than he first thought.

We can determine the loss this would cause the victim in the value discovery model under the hard-ending rule. Because of the mistake, he would begin with a bid ceiling of $\mu$ instead of $\bar{p}_{h}$. This would not affect the other bidders' optimal strategies. Informed bidders with values greater than $s^{*}$ would still lurk and snipe, while other bidders would submit their values as bid ceilings. The current winning bid would jump from zero to either $\mu$ or $s$ at the start of the game. If it jumped to $\mu$, the victim would pay to discover his value, and his bounded rationality would not have reduced his payoff. If it jumped to $s$, the victim would either win at that price or the sniper would snipe with a late bid ceiling of $s \geq s^{*}$ and win at a price of $\mu$. The loss to the victim from starting with too high a bid ceiling would come from winning too often at the price of $s$ on occasions when $v<s$.

The second mistake is to neglect the possibility of sniping. Subject to that mistake, the victim would behave the same way in the hard-ending auction as in the soft-ending auction, submitting the bid ceiling we derived for that auction, $\bar{p}_{\text {soft }}$ instead of the lower level $\bar{p}_{h}$. If the discovery cost is low, the bidder would forego the opportunity to thwart sniping by discovering his value before the auction starts. If the discovery cost is higher, he would set his discovery threshold too high, reducing from its optimal level the probability that he thwarts value discovery.

Neither kind of victim mistake has a marked effect on the predictions of the value discovery model, except that a player who fails to think about sniping will never engage in value discovery before the auction begins. Thus, the value discovery model is robust to a realistic amount of bidder irrationality.

\section{Concluding Remarks}

Value discovery explains the flurry of last-minute bidding in internet auctions as being the result of bidder ignorance of their private values. Some bidders bid late so as to prevent other bidders from having time to acquire more precise information on how much they value the object being auctioned. This also explains repeat bidding: bidders refrain from incurring the cost of thinking hard about their values until they see that bidding is high enough that such thinking is necessary.

Value discovery may have useful application to other kinds of markets. The bidder's decision in an auction parallels a consumer's decision when buying at a posted price. If he knows that the object's price is much higher than its value to him, he will not agonize over the 
exact value down to the penny, nor will he do so if the price is far less than its value. Only when the price is close to his estimate is it worthwhile to spend time and energy improving the estimate. The only difference is that in an auction the buyer must also decide whether to do his improvement in advance, for fear that the final price will be closer to his estimate than the present one. The idea that finding out one's own value for an object explains odd behavior also shows up in bargaining. In Rasmusen (2001), I model negotiation as a process in which one player makes offers whose value the other player can determine only at some cost. This usually results in a mixed-strategy equilibrium in which the offers are sometimes high and sometimes low value, and the ignorant player sometimes investigates before accepting and sometimes does not. That model does not, however, consider value discovery and the strategic response to it.

For what kind of auctions is this model reasonable? Certainly it applies to ascending auctions conducted over a long period of time (e.g., three days), such as eBay auctions. It also applies to sequential auctions, such as FCC spectrum auctions, in which sealed-bids are submitted, the current winning bid is announced, and other rounds are held till nobody wants to bid higher. But it even applies to classic English auctions like those at estate sales. The auction only lasts five minutes, but bidders must decide beforehand whether to learn the value, and if they see bidding is low at first, they can spend time- even if as little as a minutethinking harder about their private values. If, on the other hand, the bidding goes higher than expected, the interval between the last bid and the auctioneer's "Going... Going... Gone!" may be too short for value discovery. 


\section{References}

Bajari, Patrick \& Ali Hortacsu (2003) “The Winner's Curse, Reserve Prices, and Endogenous Entry: Empirical Insights from eBay Auctions," The RAND Journal of Economics, 34(2): 329-355 (Summer 2003).

Carare, Octavian \& Michael H. Rothkopf (2005) "Slow Dutch Auctions," Management Science, 51: 365-373 (2005).

Compte, Olivier \& Philippe Jehiel (2004) "The Wait-and-See Option in Ascending Price Auctions," Journal of the European Economic Association, 2(2-3): 494-503 (April-May 2004).

Compte, Olivier \& Philippe Jehiel (2005) "Auctions and Information Acquisition: Sealed-Bid or Dynamic Formats?" working paper, CERAS-ENPC, CNRS, Paris, http:/ / www.enpc.fr/ceras/jehiel/ascendRand.pdf (October 2005).

Cremer, Jacques, Yossi Spiegel \& Charles Z. Zheng (2004) "Auctions with Costly Information Acquisition," http://www.tau.ac.il/ spiegel/papers/csz24J.pdf (May 2004).

Daniel, Kent \& David Hirshleifer (1998) "A Theory of Costly Sequential Bidding," working paper, Northwestern University, July 30, 1998, http:/ / kent.kellogg.nwu.edu/papers/DH.pdf (July 23, 2001).

Easley, Robert F. \& Charles A. Wood (undated) "Bidder Strategies, Valuations, and the Winner's Curse: An Empirical Investigation," http:/ /opim-sun.wharton.upenn.edu/wise2004/sun122.pdf.

Ely, Jeff \& Tanjim Hossain "Sniping and Squatting in Auction Markets," working paper, Department of Economics Hong Kong University of Science and Technology, http:/ / ihome.ust.hk/ tanjim/squat.pdf (7 July 2006).

Engelbrecht-Wiggans, Richard (1988) “On a Possible Benefit to Bid Takers from Using Multi-Stage Auctions," Management Science, 34(9): 1109-1120 (September 1988).

Guzman, Rolando \& Charles Kolstad (1999) “Auction Equilibrium with Costly Information Acquisition," University of California-Santa Barbara Dept. of Economics working paper, http://www2.bren.ucsb.edu/\%7Ekolstad/OldPages/publications_old/aucttheo3.pdf (May 1999).

Hausch, Donald \& Li, Lode (1993) "A Common Value Auction Model with Endogenous Entry and Information Acquisition," Economic Theory, 3(2): 315-334 (April 1993).

Hossain, Tanjim (undated) "Learning by Bidding," working paper, Department of Economics, Hong Kong University of Science and Technology, Hong Kong, http://ihome.ust.hk/ tanjim/LBB_v4.pdf. 
Janssen, Maarten \& Eric Rasmusen (2002) "Bertrand Competition Under Uncertainty," The Journal of Industrial Economics, 50(1): 11-21 (March 2002).

Ku, Gillian, Deepak Malhotra \& J. Keith Murnighan (2005): “Towards a Competitive Arousal Model of Decision Making: A Study of Auction Fever in Live and Internet Auctions," Organizational Behavior and Human Decision Processes, 26: 89-103.

Larson, Kate \& Tuomas Sandholm (2001) "Costly Valuation Computation in Auctions," Proceedings of the Theoretical Aspects of Reasoning about Knowledge (TARK), pp. 169-182. http://www.cs.cmu.edu/ sandholm/tark01.pdf.

Levin, Dan \& James L. Smith, (1994) “Equilibrium in Auctions with Entry," The American Economic Review, 84(3): 585-599 (June 1994).

Ockenfels, Axel \& Alvin E. Roth (2003) "Late Bidding in Second Price Internet Auctions: Theory and Evidence Concerning Different Rules for Ending an Auction" forthcoming, Games and Economic Behavior, http:/ /ockenfels.uni-koeln.de/download/papers/ockenfels-roth.pdf (May 27, 2003).

Persico, Nicola (2000) "Information Acquisition in Auctions," Econometrica, 68(1): 135-148 (January 2000).

Rasmusen, Eric (2001) “Explaining Incomplete Contracts as the Result of Contract-Reading Costs," Advances in Economic Analysis and Policy, Vol. 1: No. 1, Article 2, http://www.bepress.com/bejeap/advances/vol1/iss1/art2 (2001).

Rasmusen, Eric (2005) "Getting Carried Away in Auctions as Imperfect Value Discovery," working paper, Indiana University, http:/ / rasmusen.org/papers/carried-rasmusen.pdf.

Rezende, Leonardo (2005) "Mid-Auction Information Acquisition," University of Illinois working paper, http:/ / www.econ.puc-rio.br/pdf/rezende.pdf (31 August 2005).

Roth, Alvin E. \& Axel Ockenfels (2002) "Last Minute Bidding and the Rules for Ending Second-Price Auctions: Evidence from eBay and Amazon Auctions on the Internet," The American Economic Review, 92(4): 1093-1103 (September 2002).

Sandholm, Tuomas (2000) "Issues in Computational Vickrey Auctions," International Journal of Electronic Commerce, 4(3): 107-129, http:/ / www.cs.cmu.edu/ sandholm/vickrey.IJEC.pdf (2000).

Schindler, Julia (2003) “Late Bidding on the Internet," University of Vienna working paper, http:/ / www.econ.kuleuven.be/smye/abstracts/p316.pdf (March 2003).

Wang, Tao-yi Joseph (2003) “Is Last Minute Bidding Bad?" working paper, Department of Economics, UCLA, http:/ / www.econ.kuleuven.be/smye/abstracts/p660.pdf (March 14, 2003). 
Wilcox, Ronald (2000) "Experts and Amateurs: The Role of Experience in Internet Auctions," Marketing Letters, 11(4): 363-374 (November 2000). 